\title{
Jolanta Maćkiewicz
}

Uniwersytet Gdański

ORCID: 0000-0003-3998-2294

\section{Badanie ram multimodalnych - rekonesans}

\begin{abstract}
Streszczenie
Artykuł poświęcono sposobom badania ram interpretacyjnych w tekstach medialnych. Zakłada się, że uszystkie te teksty są polisemiotyczne, zatem i ramy muszą być multimodalne. Próbuję odpouiedzieć na cztery pytania: jaką metodologię wykorzystywać, jak dobrać jednostkę analizy, jakie środki ramowania uwzględniać, jak opisywać współdziałanie środków werbalnych i niewerbalnych.
\end{abstract}

Słowa kluczowe: rama, ramowanie, mulimodalność, rama multimodalna, rama medialna, media.

\section{Study of multimodal frames - reconnaissance}

\section{Abstract}

The article is devoted to the methods of researching interpretative frames in media texts. Since it is assumed that all these texts are polisemiotic the frames themselves must be multimodal. I try to answer four questions: what kind of methodology should be used; how to choose the unit of analysis; which framing devices should be taken into account; how to describe the cooperation between verbal and non-verbal devices.

Keywords: frame, framing, multimodality, multimodal frame, media frame.

\section{Wprowadzenie}

Wpraudzie historia użycia określenia frame (polski odpowiednik: rama) w naukach humanistycznych i społecznych liczy już niemal pół wieku ${ }^{1}$, jednak nadal termin ten jest wieloznaczny i nieostry zakresowo. Wynika to nie tylko z jego metaforyczności i (pozornej?) bliskoznaczności z innymi terminami, takimi jak na przykład schemat, lecz także z tego, że termin frame jest uykorzystywany w różnych dyscyplinach naukouych (takich jak psychologia, socjologia, językoznaustwo, politologia, nauki o komunikacji, medioznawstwo), a nawet - w różnych znaczeniach w obrębie jednej dyscypliny².

W dodatku nie do końca zostały rozstrzygnięte metodologiczne kuestie związane z zastosowaniem tego narzędzia do badania tekstów i/lub faktów społecznych. Uwagi

1 Termin frame został użyty w połowie lat siedemdziesiątych ubiegłego wieku w językoznawczych pracach Charlesa Fillmore'a i w socjologicznych pracach Ervinga Goffmana.

${ }^{2}$ Więcej na ten temat zob. J. Maćkiewicz, Ramy interpretacyjne jako narzędzie badań medioznawczych, „Studia Medioznawcze” 2020, t. 21, nr 3, s. 615-627. 
wymaga zułaszcza problem ram multimodalnych, a właściwie - ram realizowanych multimodalnie.

Celem tego artykułu jest przyjrzenie się możliwym sposobom badania ram interpretacyjnych i zastanowienie się, które z tych sposobów najlepiej nadają się do badania multimodalnych ram zawartych w tekstach medialnych.

\section{Ramy medialne - ramy multimodalne}

Ramy interpretacyjne rozumiane jako schematy porządkujące rzeczyuistość i narzucające/sugerujące sposób jej postrzegania można odnaleźć u czterech różnych miejscach procesu komunikacyjnego: u nadawcy, który świadomie lub nieświadomie odwołuje się do ram rezydujących w jego systemie przekonań i wierzeń, w tekście, gdzie środki werbalne i ikoniczne sygnalizują istnienie ram, u odbiorcy, który interpretuje komunikat zgodnie z systemem schematów poznawczych istniejących w jego umyśle, i - wreszcie w kulturze, będącej zbiorem ram przywoływanych w dyskursie ${ }^{3}$. W dalszej części artykułu interesować nas będzie poszukiwanie ram w tekście, a ściślej - w tekstach medialnych. Takie ramy nazyua się ramami medialnymi (media frames).

Ramy medialne są to zatem, według Stephena D. Reese'a, schematy interpretacyjne, do których docieramy poprzez medialne teksty ${ }^{4}$, przy czym - [t]he frame is not the same as its symbolic manifestation... ${ }^{5}$ [rama nie jest tym samym, co jej symboliczne wyrażenie - tłum. J.M.]. Oznacza to, że jedna i ta sama rama może być uyrażana (czy: uspółuyrażana) za pomocą rozmaitych środków, również - środków należących do rozmaitych kodów symbolicznych.

W prowadzonych do tej pory badaniach ram interpretacyjnych koncentrowano się najczęściej na środkach werbalnych. Jeśli nawet uwzględniano środki wizualne (pisząc o visual framing ${ }^{6}$ ), to były to jedynie fotografie, przy tym - fotografie bądź analizowane w izolacji ${ }^{7}$, bądź z uuzględnieniem jedynie podpisóu pod zdjęciami czy nagłóuków ${ }^{8}$.

\footnotetext{
${ }^{3}$ R.M. Entman, Framing: Towards Clarification of a Fractured Paradigm, „Journal of Communication" 1993, nr 43(4), s. 52-53.

4 S.D. Reese, Prologue - Framing Public Life: A Bridging Model for Media Research [w:] Framing Public Life: Perspectives on Media and Our Understanding of the Social World, red. S.D. Reese, O.H. Gandy, A.E. Grant, Routledge, London 2001, s. 14.

${ }^{5}$ Ibidem.

${ }^{6}$ „Visual framing należy [...] rozumieć jako taki sposób fotograficznej prezentacji danego uydarzenia czy problemu, który narzuca sposób interpretacji zobrazowanej treści”. Zob. J. Szylko-Kwas, Wizerunki Prezydentów Rzeczpospolitej Polskiej: Bronisława Komorowskiego oraz Andrzeja Dudy - analiza porównawcza w świetle teorii visual framing, „Res Rhetorica” 2019, nr 6(1), s. 34.

7 Zob. na przykład S. Fahmy, Contrasting Visual Frames of Our Times: A Framing Analysis of English- and Arabic-language Press coverage of War and Terrorism, „The International Communication Gazette” 2010, nr 72(8), s. 695-717; J. Szylko-Kwas, op. cit., s. 30-50.

${ }^{8}$ K. Perry, A Visual Framing Analysis of British Press Photography during the 2006 Israel-Lebanon Conflict, „Media, War \& Conflict” 2010, nr 3(1), s. 67-85.
} 
Jeśli jednak wyjdziemy z założenia, że ramy to sterujące interpretacją struktury pojęciowe ukryte $\mathrm{w}$ szeroko rozumianych tekstach (tekstem $\mathrm{w}$ takim rozumieniu będzie i program telewizyjny, i portal internetowy), to powinniśmy uwzględnić fakt, że te teksty są współtworzone przez kilka kodów semiotycznych, które nie funkcjonują niezależnie od siebie. Przy czym wszystkie teksty medialne mają charakter mniej czy bardziej polisemiotyczny (czasem także - jak przekazy telewizyjne - polisensoryczny). Wynika z tego, że - poszukując ram - trzeba brać pod uwagę uszystkie kody składające się na komunikat oraz - dodatkowo - relacje między nimi. Przyjmuje się tu z jednej strony koncepcję swoistego podziału pracy, zakładając że „...każdy system znaków jest zupełnie inny i posiada swój potencjał wypowiedzi, a co za tym idzie, realizuje u tekście multimodalnym określone zadania", z drugiej - przekonanie o tym, że współistnienie różnych kodów tworzy układ skomplikowanych powiązań i skutkuje stworzeniem semantycznej całości, która nie jest prostą sumą swoich składników (mamy do czynienia z efektem komunikacyjnej synergii, wzajemna kontekstualizacja stwarza dodatkowe znaczenia, których nie mają poszczególne elementy).

Jak zatem badać medialne ramy multimodalne? Rozstrzygnięcia wymaga kilka zagadnień.

Po pierwsze, jaką metodologię wykorzystywać.

Po drugie, jak dobrać jednostkę analizy.

Po trzecie, na jakie środki ramowania zuracać uwagę w poszczególnych systemach semiotycznych.

Po czwarte, jak opisywać uspółdziałanie środków werbalnych i niewerbalnych.

\section{Badanie ram multimodalnych - metodologia}

Przy rekonstruowaniu medialnych ram interpretacyjnych badacz zazwyczaj dokonuje następujących wyborów:

- pomiędzy metodą indukcyjną a dedukcyjnąi

- pomiędzy metodami ilościouymi a jakościouymi (można je też łączyć).

Jakie metody najlepiej sprawdziłyby się przy rekonstruowaniu medialnych ram multimodalnych?

Pragnąc wydobyć ramy realizujące się multimodalnie, należałoby wyjść od metody indukcyjnej polegającej na szczegółouym badaniu środków, które należą do różnych kodów semiotycznych (słowa, obrazy nieruchome czy ruchome, dźwięki...). Byłoby to badanie zasadniczo jakościowe, co najwyżej uspomagane przez metody ilościowe.

\footnotetext{
${ }_{9}^{9}$ H. Stöckl, Lingwistyka mediów. O statusie i metodach (wciąż) konstytuującej się dyscypliny badawczej [w:] Lingwistyka mediów. Antologia tłumaczeń, red. R. Opiłouski, J. Jarosz, P. Stanieuski, Oficyna Wydawnicza Atut - Wrocłauskie Wydawnictuo Ośuiatowe-Neisse Verlag, Wrocław-Dresden 2015, s. 118.

${ }_{10}$ Zob. W.A. Gamson, A Constructionist Approach to Mass Media and Public Opinion, „Symbolic Interaction” 1988, nr 11, s. 161-174.
} 
Analiza każdego tekstu przebiegałaby w dwóch etapach: etap pierwszy to wydobycie środków ramowania (osobno dla każdego systemu semiotycznego), etap drugi to próba uporządkowania tych środków wedle pewnych wyłaniających się $\mathrm{w}$ trakcie badania pojęć ${ }^{11}$. Wydaje się, że przydatne mogłoby się okazać rozumienie ramy interpretacyjnej jako uiązki pojęć z centrum i obszarami peryferycznymi ${ }^{12}$. W tym drugim etapie byłyby uwzględniane relacje między środkami należącymi do różnych kodów.

\section{Badanie ram multimodalnych - jednostka analizy}

Wybór jednostki analizy zależy przede uszystkim od rodzaju materiału, jaki się będzie badać. Materiał prasowy, programy telewizyjne, przekazy internetowe - każdy z tych rodzajów wymaga odmiennej segmentacji. W każdym jest wykorzystywany inny układ kodów semiotycznych (np. w telewizji: obraz ruchomy, obraz nieruchomy, słowo, dźwięk). Inaczej też przebiega proces odbioru nadawanych komunikatów. Hans-Júrgen Bucher rozróżnia trzy typy form komunikacji medialnej: linearne, na przykład audycje radioue, filmy TV; nielinearne, na przykład portale internetowe, prasa i hybrydowe (z elementami linearnymi i nielinearnymi), na przykład programy TV z dodatkami wizualnymi czy portale internetoue z materiałami uideo ${ }^{13}$.

Poszukując jednostek analizy, należałoby zatem wziąć pod uwagę następujące czynniki:

- po pierusze, ile i jakie systemy semiotyczne są uwzględniane;

- po drugie, czy mamy do czynienia z przekazem linearnym, czy nielinearnym, nieciągłym (np. w periodykach okładka odsyła do wnętrza numeru, stanowi więc nieodłączną część jednego z artykułów).

Musimy też pamiętać o tym, że chcąc zrekonstruować ramy uyrażane multimodalnie, powinniśmy uybierać w miarę obszerne całości, w których różne kody semiotyczne współdziałają ze sobą.

W dodatku należałoby przyjąć zasadę, że analizowane teksty nie są jednorodne pod uzględem informacyjności. W każdym tekście występują bowiem elementy czy miejsca, które można by nazwać strategicznymi, elementy strategiczne będące nośnikami treści szczególnie ważnych dla przekazu. Na przykład dla artykułów prasouych byłby to nagłówek, lid, wyimek, akapit końcouy, główne zdjęcie wraz z podpisem, infografika ${ }^{14}$.

\footnotetext{
${ }_{11}$ Baldwin Van Gorp w suoim projekcie badauczym określa to jako różnicę między open coding i axial coding. Zob. B. Van Gorp, Strategies to Take Subjectivity Out of Framing Analysis [w:] Doing News Framing Analysis. Empirical and Theoretical Perspectives, red. P. D'Angelo, J.A. Kuypers, New York-London 2010, s. 84-109.

12 Zob. J.K. Hertog, D.M. McLeod, A Multiperspectival Approach to Framing Analysis: A Field Guide [w:] Framing Public Life..., op. cit., s. 139-161.

${ }^{13}$ H.-J. Bucher, Rozumienie multimodalne lub recepcja jako interakcja [w:] Lingwistyka mediów. Antologia tłumaczeń, op. cit., s. 82.

14 Niektórzy badacze tekstów prasowych przyjmowali tu zasadę „odwróconej piramidy”, stwierdzając: An inverted pyramid refers to a sequential organization of structural elements (i.e. headline, lead, episodes, background, and closure). The signifying power of these elements
} 
Dla newsów składających się na telewizyjny serwis informacyjny - wprowadzenie prezentera, paski informacyjne, materiał filmowy. Elementy strategiczne zazwyczaj są uwydatniane przez layout (w prasie), rozmieszczenie czasowe: kolejność i sąsiedztwo (w telewizji) czy strukturę nawigacyjną (w internetowym hipertekście). W ten sposób przyciągana jest uwaga odbiorcy, a zatem należy zakładać, że właśnie w tych miejscach nadawca będzie umieszczał sygnały kierujące procesem interpretacyjnym.

\section{Badanie ram multimodalnych - środki ramowania}

Jakie środki ramowania uwzględniać w pieruszym etapie analizy?

Jeśli chodzi o środki werbalne, należałoby rozróżnić kilka ich poziomów. Przede wszystkim poziom czysto leksykalny, czyli tzw. słowa-klucze. O ich przydatności w rekonstruowaniu ram pisze wielu badaczy ${ }^{15}$. Jak jednak rozumieć ten termin w odniesieniu do analizy ramowania? Wydaje się, że nie w jego klasycznym relacyjnym sensie zaproponowanym przez Pierre’a Guirauda ${ }^{16}$, lecz jako wyrazy tematyczne, uybierane ze uzględu na to, że nazywają kluczowe dla tekstu pojęcia (byłyby to określenia dotyczące głóunego problemu, bohaterów i antybohaterów itd., czyli słowa-desygnatory $\left.{ }^{17}\right)$. Częstość ich pojawiania się w tekście jest kuestią dość istotną (można posłużyć się ilościouymi metodami badania), lecz nie najważniejszą, wtórną. Może bowiem zdarzyć się tak, że najlepiej definiujące problem słowo (na przykład wyrażenie metaforyczne, które odwołuje się do wspólnej wiedzy kulturowej) wystąpi w analizowanym tekście tylko raz, lecz będzie na tyle wyraziste, że stanie się podstawowym punktem dostępu do ramy. Tak rozumiane słowa-klucze pouinny być rozpatrywane u kontekście, u kolokacjach (zułaszcza jeśli chodzi o łączliwość z określeniami o charakterze oceniającym).

Ale nie tylko pojedyncze wyrazy powinny być brane pod uwagę. Istotne są również metafory i metonimie, kulturowe symbole, skrzydlate słowa, (historyczne) przykłady czy odniesienia do stereotypów.

varies in the same descending order. Z. Pan, G.M. Kosicki, Framing Analysis: An Approach to News Discourse, „Political Communication” 1993, nr 10, s. 64. Jednakże, jak zauważył Tomasz Piekot, zasada odwróconej piramidy nie zausze musi być główną strategią porządkującą tekst. Zob. T. Piekot, Dyskurs polskich wiadomości prasowych, Towarzystwo Autorów i Wydauców Prac Naukouych Universitas, Kraków 2006, s. 163-184.

15 Zob. na przykład R.M. Entman, op. cit., s. 52 czy S.D. Reese, Finding Frames in a Web of Culture. The Case of the War on Terror [w:] Doing News..., op. cit., s. 20.

${ }_{16}$ P. Guiraud (Les caractéres statistiques du vocabulaire, Presses Universitares de France, Paryż 1954) definiował słowa-klucze jako wyrazy, które u danym tekście mają „zawyżoną” frekuencję, to znaczy frekwencję wyższą niż ta przeciętna, podana w słowniku frekwencyjnym. ${ }_{17}$ Very often, lexical choices of words or labels are made to designate one of the categories in syntactic or script structures. We will call the resulting choice a "designator" because it functions to establish a correspondence between a signifier and "signified" as well as allocating the signified in a specific cognitive category. The latter, being contingent on the former, often signifies the presence of a particular frame. A large portion of choosing a designator involves labeling, which reveals cognitive categorizations on the part of newsmakers. Z. Pan, G.M. Kosicki, op. cit., s. 62. 
Na poziomie tekstowym ważny jest sposób prowadzenia narracji ${ }^{18}$ i sposób cytowania. Sposób prowadzenia narracji może się różnić u zależności typu medium, od medialnego gatunku (inaczej porządkowana jest treść w gatunkach informacyjnych i publicystycznych), od funkcji dominującej w danym medium czy danym przekazie (chodzi między innymi o mniejszy czy większy udział infotainment, stopień tabloidowości...19), od rodzaju i istotności problematyki. Poszukując w narracji wyznaczników ramy interpretacyjnej, nie można zapomnieć o tych uwarunkowaniach. Schemat narracyjny wyznacza głównych aktorów, którym przypisuje określone role, określa relacje między aktorami (np. konflikt) i ich stosunek do omawianej kuestii. Schematy mogą być mniej lub bardziej dramatyczne, mniej lub bardziej nacechowane emocjami.

W przypadku cytowania istotne jest, kogo się dopuszcza do głosu i w jaki sposób się cytuje.

A jakie mogą być wizualne środki ramowania?

Zacząć trzeba od tego, jakie elementy obrazowe można uwzględniać. Przede wszystkim należałoby odróżnić dwa ich typy: z jednej strony niewerbalne środki funkcjonujące wraz z tekstem werbalnym, w jego obrębie, z drugiej strony elementy posiadające (względną) niezależność.

Wśród tych ostatnich w tekstach prasowych można odnaleźć sześć ich rodzajów: fotografie dokumentalne (reporterskie), fotografie portretowe, fotografie kreowane (kreacyjne, inscenizowane, aranżowane), fotomontaże, rysunki oraz infografikę. W przekazach telewizyjnych będą to głównie obrazy dynamiczne (choć niewykluczone są również statyczne). W internetowym hipertekście - zarówno obrazy nieruchome wszystkich wymienionych wcześniej rodzajów, jak i obrazy ruchome. Każdy z tych elementów może być uykorzystywany do sygnalizowania ram interpretacyjnych. Warto jednak zastanowić się nad uwzględnianiem bądź nie elementów pieruszego typu, do których w tekstach prasowych należą layout i typografia. Choć nie unoszą one nowych znaczeń, to jednak uwydatniają, podkreślają treści sygnalizowane przez słowa i obrazy, a przecież uwydatnianie (salience) to jeden z przejawów ramowania.

Zatrzymajmy się przy fotografiach, bo właśnie o nich napisano najwięcej. W badaniach visual framing uwzględniano tematykę zdjęć (ważny jest również sposób ujęcia tej tematyki ${ }^{20}$ i sposób kadrowania ${ }^{21}$. W obu przypadkach najistotniejsza jest kwestia

\footnotetext{
${ }^{18}$ Rozumienie sposobu prowadzenia narracji jako jednego z narzędzi ramowania zbliża się do określenia script structure zaproponowanego przez Zhondanga Pana i Geralda M. Kosickiego (op. cit., s. 60). Jest to rozumienie szerokie, ponieważ obejmuje nie tylko typowe opowieści, lecz także wszelkie układy treści, które organizują teksty medialne.

${ }_{19}$ Jest to ważne, ponieważ przy rekonstruowaniu ram chodzi róunież o oddzielenie tego, co wynika z konwencji medialnych, o rozróżnienie treści warunkowanych ideologicznie i tych wynikających z właściwego uspółczesnym mediom nastawienia na przyciągnięcie odbiorcy poprzez sensacyjność i emocjonalność komunikatu.

${ }_{20}^{20}$ T. Piekot rozróżnia dwa sposoby ujmowania tematu: wizualizację realistyczną i symboliczną. Zob. T. Piekot, op. cit., s. 123-133.

${ }^{21}$ Zob. m.in. S. Fahmy, op. cit., K. Perry, op. cit., J. Szylko-Kwas, op. cit.
} 
wyboru - wyboru tego, co i jak będzie fotografowane. Jak podkreśla David duChemin: „Wewnątrz kadru poustaje odrębny świat”22 i dalej doprecyzouuje:

Tworzymy, zamykając wewnątrz kadru niewielkie części i sugerujemy relacje nigdy niespotykane u rzeczywistości. Odcinając uszystko, co otacza fotografowany przedmiot, kierujemy uwagę widzów na to, co mieści się w kadrze. Pokazujemy więcej, pokazując mniej²3.

Jeśli chodzi o sposób kadrowania, trzeba uziąć pod uwagę przede uszystkim typ planu (plan pełny, średni bądź zbliżenie) oraz rodzaj perspektyuy: różnicę między perspektywą „żabią” (ujęcie z dołu) a „ptasią” (ujęcie z góry). Istotna bywa też ostrość ujęcia oraz sposób naświetlenia. Każdy z tych uyborów pociąga za sobą zasugerowanie czy uręcz narzucenie odbiorcy określonej interpretacji przedstawianej sceny ${ }^{24}$.

Wydaje się, że w przypadku zdjęć przedstawiających ludzi należałoby przyjrzeć się również mimice i gestykulacji, jako że uchwycenie bohatera tekstu w takim a nie innym momencie często śuiadczy o stosunku do niego i stanowi komponent jego charakterystyki.

Pamiętajmy też, że selekcjonowanie nie kończy się na etapie robienia zdjęcia. Fotograf dokonuje uyboru ujęcia, lecz to redaktor decyduje o tym, która fotografia będzie ilustrowała tekst ${ }^{25}$.

Przytoczone uwagi dotyczą głównie fotografii dokumentalnych (i materiału filmowego w wiadomościach telewizyjnych). Przemyślenia wymaga sposób uwzględniania pozostałych typów elementów obrazowych, które różnią się stopniem kreacyjności (od fotografii kreowanej, poprzez fotomontaż, po rysunek) i stopniem odwołań do emocji bądź intelektu (infografika).

\section{Multimodalne badanie ram - specyfika}

Przekonanie o istnieniu ram multimodalnych oznacza nie tylko, że ramy interpretacyjne mogą być wyrażane za pomocą różnych systemów semiotycznych, lecz także - że badanie tych ram powinno mieć charakter multimodalny. Na czym takie badanie mogłoby polegać?

${ }^{22}$ D. duChemin, Język fotografii. Rozważania o tworzeniu mocniejszych zdjęć, przeł. W. Tkaczyński, Galaktyka, Łódź 2012, s. 17.

${ }^{23}$ Ibidem, s. 18.

${ }^{24}$ T. Piekot pisze o wizualizacji symbolicznej z użyciem środków technicznych. Zob. T. Piekot, op. cit., s. 130-133.

${ }^{25}$ Jak podkreśla Carol B. Schwalbe: Visual framing is a continuous winnowing process. It begins with the choice of events to cover, followed by the selection of what pictures to take, how to take them (angle, perspective, assumptions and biases, and so forth), and which ones to submit. I dalej:...the process continues in the newsroom with decisions about which images to publish, what size to make them, and where to position them on the page. Zob. C.B. Schwalbe, Remembering our Shared Past: Visually Framing the Iraq War on U.S. News Websites, „Journal of Computer-Mediated Communication” 2006, nr 12, s. 269. 
Rick Iedema podaje cztery cechy charakteryzujące multimodalne podejście do analizy tekstów:

- uuzględnia u analizie inne systemy semiotyczne niż język i kładzie nacisk na ich traktowanie z należytą uwagą;

- analizuje relacje między różnymi systemami semiotycznymi i ich «podział pracy» w przekazywaniu treści w konkretnych reprezentacjach;

- dąży do poznania, zrozumienia i opisania «filogenezy» procesu zastępowania określonych systemów semiotycznych innymi (np. zastępowanie języka obrazem);

- łączy potencjał danych systemów semiotycznych ze sposobem, w jaki upływają na (tj. rozwijają lub ograniczają) interakcję i kształtowanie subiektywności ${ }^{26}$.

Jak zastosować te zasady do wyodrębniania ram interpretacyjnych? Istotne jest przede uszystkim przyjęcie zasady, że nie tylko uwzględnia się różne systemy semiotyczne, lecz także bierze się pod uwagę relacje między nimi.

Jakie to mogą być typy relacji? Po pierusze, treści uprowadzane przez różne kody semiotyczne mogą być paralelne (np. obraz poutarza - za pomocą innych środków, a zatem i tak nieco inaczej - to, co zostało zawarte w tekście werbalnym). Po drugie, treści te mogą ze sobą współdziałać: mogą się uzupełniać lub (wzajemnie) reinterpretować (ale także - obraz może stanowić niejako syntezę, streszczenie tekstu werbalnego). W dość rzadkich przypadkach - słowo i obraz (bo już nie np. obraz i dźwięk) mogą funkcjonować niezależnie od siebie ${ }^{27}$, czasem element obrazowy (lub dźwiękowy) może służyć wyłącznie przyciągnięciu uwagi.

Najbardziej rozbudowaną propozycję metodologiczną w tym względzie przedstawili Radan Martinec i Andrew Salway, którzy opisywali relacje między słowem a obrazem (a ściślej: fotografiami) u tekście prasowym ${ }^{28}$. Odwołują się oni do semiotycznej koncepcji Rolanda Barthesa ${ }^{29}$ i językoznawczej koncepcji M.A.K. Hallidaya ${ }^{30}$. Rozróżniają ze względu na udział poszczególnych kodów relacje równorzędne i nierównorzędne ${ }^{31}$,

${ }^{26}$ R. Iedema, Multimodalna analiza dyskursu: Resemiotyzacja na potrzeby dyskursów użytkowych [w:] Systemowo-funkcjonalna analiza dyskursu, red. A. Duszak, G. Kowalski, przeł. M. Żelewa, Touarzystwo Autorów i Wydawców Prac Naukowych Universitas, Kraków 2013, s. 217.

${ }_{27}$ Paul Messaris i Linus Abraham zauważają, że ramowanie wizualne może przekazywać bardziej kontrowersyjne treści niż te przekazywane słowami. Zob. P. Messaris, L. Abraham, The Role of Images in Framing News Stories [w:] Framing Public Life, op. cit., s. 215.

${ }_{28}$ R. Martinec, A. Salway, A System for Image-Text Relations in New (and Old) Media, „Visual Communication" 2005, nr 4(3), s. 338-371.

${ }^{29}$ Roland Barthes pisał o trzech typach relacji między tekstem a obrazem: gdy tekst „zakotwicza” (anchorage), ujednoznacznia wieloznaczny z natury obraz, gdy obraz ilustruje tekst (illustration) i gdy tekst jest „przekaźnikiem” (relay), współpracującym z obrazem w tworzeniu całościouego komunikatu. Zob. R. Barthes, The Rhetoric of the Image [w:] idem, Image - Music - Text, Hill and Wang, London 1977, s. 152-163.

${ }^{30}$ Zob. M.A.K. Halliday, Explorations in the Functions of Language, Edward Arnold, London 1973.

${ }^{31}$ Relacje są nieróunorzędne, gdy jeden z elementóu modyfikuje drugi. Relacje są róunorzędne, kiedy oba elementy są równie istotne. Równorzędność dotyczy zarówno sytuacji, gdy oba elementy są od siebie niezależne (independent), jak i tych, gdy się uzupełniają (complementary). Ibidem, s. 343. 
a ze względu na typ semantycznego związku: elaborację/opracowanie (elaboration), rozuinięcie (extension) i uwydatnienie (enhancement) ${ }^{32}$. Elaboracja to przedstawienie tej samej treści na różne sposoby, czasem na tym samym poziomie ogólności (wtedy jest to exposition 'ekspozycja, przedstawienie'), czasem na różnych poziomach (wóuczas jest to exemplification 'egzemplifikacja') ${ }^{33}$. Rozwinięcie to rozszerzenie, uzupełnienie informacji (zazwyczaj to tekst rozwija informację zawartą w obrazie) ${ }^{34}$. Uuydatnienie polega na tym, że jeden z elementów doprecyzourje drugi pod względem okoliczności, takich jak czas, miejsce i przyczyna lub cel ${ }^{35}$.

Rekonstruując ramy zawarte w multimodalnych przekazach, należałoby zestawiać ze sobą treści unoszone przez różne typy środków, poszukiwać podobieństu między tymi treściami, łączyć je w znaczeniowe grupy, a następnie porządkować.

\section{Rama multimodalna jako wiązka pojęciowa}

Na czym miałoby polegać porządkowanie?

Jőrg Matthes i Matthias Kohring zakładają, że każda rama składa się z kilku elementów, a każdy element zawiera kilka analitycznych zmiennych ${ }^{36}$. Poszukując tych elementów, wychodzą od definicji ramowania zaproponowanej przez R.M. Entmana:

To frame is to select some aspects of a perceived reality and make them more salient in a communicating text, in such a way as to promote a particular problem definition, causal interpretation, moral evaluation, and/or treatment recommendation $^{37}$. [Ramować to znaczy uybierać pewne aspekty postrzeganej rzeczywistości i uuypuklać je u tekście komunikacyjnym, tak aby promować określoną definicję problemu, interpretację przyczynowo-skutkową, ocenę moralną i/lub zalecać sposób zachowania względem problemu - tłum. J.M.].

Na ramę składałyby się zatem następujące elementy:

- sposób zdefiniounania problemu, będącego głóunym tematem tekstu (także - wyodrębnienie i nazwanie głównych aktorów);

- interpretacja przyczynowo-skutkowa (co jest przyczyną danego problemu, jakie mogą być pozytywne lub negatywne skutki i kto jest za to odpowiedzialny);

- ocena moralna (ważne jest nie tylko to, jaka to ocena, lecz róunież do kogo/do czego się odnosi);

- zalecany sposób zachowania (na przykład wezwanie do określonego działania) ${ }^{38}$.

Nie uszystkie elementy muszą być obecne w każdej ramie interpretacyjnej, uydaje się, że obowiązkowy jest tylko ten pieruszy, przy czym nie należy zapominać o tym,

32 Ibidem, s. 349-351.

${ }^{33}$ Ibidem, s. 350.

34 Ibidem.

${ }^{35}$ Ibidem, s. 350-351.

${ }^{36}$ J. Matthes, M. Kohring, The Content Analysis of Media Frames: Toward Improving Reliability and Validity, „Journal of Communication” 2008, nr 58, s. 264.

${ }^{37}$ R.M. Entman, op. cit., s. 52.

38 J. Matthes, M. Kohring, op. cit., s. 264. 
że zaróuno zdefiniowanie problemu, jak i pozostałe składniki ramy mogą być uyrażone w sposób metaforyczny - za pomocą metafory pojęciowej. Jeden z tych komponentów (zazuyczaj: nazwanie/zdefiniowanie problemu) stanowi - zgodnie z koncepcją J.K. Hertoga i D.M. McLeoda ${ }^{39}$ - centrum interpretacyjnej wiązki pojęciouej. Właśnie liczba wyodrębnionych elementów, powiązania między nimi i sposób ich wypełnienia tworzą multimodalną ramę medialną.

\section{Podsumowanie}

Z poczynionych rozważań wypływają następujące unioski co do badania multimodalnych ram medialnych.

Po pierusze, jeśli chodzi o metodologię, wydaje się, że bardziej przydatne byłyby metody indukcyjne i jakościoue (co najwyżej uspomagane badaniami ilościowymi).

Po drugie, wybór jednostki analizy zależy, jak można sądzić, u głównej mierze od typu medialnych tekstów branych pod uwagę.

Po trzecie, należałoby brać pod uwagę zaróuno leksykalne, jak i tekstowe wyznaczniki ramy oraz szeroką gamę środków obrazowych (zastanowienia wymaga sprawa ewentualnego uwzględniania layoutu i typografii).

Po czwarte, aby opisać uspółdziałanie środków werbalnych i niewerbalnych, można posłużyć się koncepcją wiązki pojęciowej.

Wszystkie te założenia wymagają spraudzenia na możliwie obszernym i zróżnicowanym materiale medialnym.

\section{Bibliografia}

Barthes R., The Rhetoric of the Image [w:] R. Barthes, Image-Music-Text, Hill and Wang, London 1977, s. 152-163.

Bucher H.-J., Rozumienie multimodalne lub recepcja jako interakcja [w:] Lingwistyka mediów. Antologia tłumaczeń, red. R. Opiłouski, J. Jarosz, P. Stanieuski, Oficyna Wydawnicza Atut - Wrocłauskie Wydaunictuo Oświatowe-Neisse Verlag, Wrocław-Dresden 2015, s. $79-110$.

duChemin D., Język fotografii. Rozważania o tworzeniu mocniejszych zdjęć, przeł. W. Tkaczyński, Galaktyka, Łódź 2012.

Entman R.M., Framing: Towards Clarification of a Fractured Paradigm, „Journal of Communication" 1993, nr 43(4), s. 51-58.

Fahmy S., Contrasting Visual Frames of Our Times: A Framing Analysis of English- and Arabic-language Press coverage of War and Terrorism, „The International Communication Gazette" 2010, nr 72(8), s. 695-717.

Gamson W.A., A Constructionist Approach to Mass Media and Public Opinion, „Symbolic Interaction" 1988, nr 11, s. 161-174.

${ }_{39}$ J.K. Hertog, D.M. McLeod, op. cit. 
Guiraud P., Les caractéres statistiques du vocabulaire, Presses Universitares de France, Paryż 1954.

Halliday M.A.K., Explorations in the functions of language, Edward Arnold, London 1973.

Hertog J.K., McLeod D.M., A Multiperspectival Approach to Framing Analysis: A Field Guide [w:] Framing Public Life: Perspectives on Media and Our Understanding of the Social World, red.. S.D. Reese, O.H. Gandy, A.E. Grant, Routledge, London 2001, s. 139-161.

Iedema R., Multimodalna analiza dyskursu: Resemiotyzacja na potrzeby dyskursów użytkowych [w:] Systemowo-funkcjonalna analiza dyskursu, red. A. Duszak, G. Kowalski, przeł. M. Żelewa, Towarzystwo Autorów i Wydauców Prac Naukouych Universitas, Kraków 2013, s. 197-227.

Maćkiewicz J., Ramy interpretacyjne jako narzędzie badań medioznawczych, „Studia Medioznawcze" 2020, t. 21, nr 3, s. 615-627.

Martinec R., Salway A., A System for Image-Text Relations in New (and Old) Media, „Visual Communication" 2005, nr 4(3), s. 338-371.

Matthes J., Kohring M., The Content Analysis of Media Frames: Toward Improving Reliability and Validity, „Journal of Communication” 2008, nr 58, s. 258-279.

Messaris P., Abraham L., The Role of Images in Framing News Stories [w:] Framing Public Life: Perspectives on Media and Our Understanding of the Social World, red. S.D. Reese, O.H. Gandy, A.E. Grant, London 2001, s. 215-226.

Pan Z., Kosicki G.M., Framing Analysis: An Approach to News Discourse, „Political Communication" 1993, nr 10, s. 55-75.

Perry K., A Visual Framing Analysis of British Press Photography during the 2006 Israel-Lebanon Conflict, „Media, War \& Conflict” 2010, nr 3(1), s. 67-85.

Piekot T., Dyskurs polskich wiadomości prasowych, Towarzystwo Autorów i Wydawców Prac Naukouych Universitas, Kraków 2006.

Reese S.D., Finding Frames in a Web of Culture. The Case of the War on Terror [w:] Doing News Framing Analysis. Empirical and Theoretical Perspectives, red. P. D'Angelo, J.A. Kuypers, Routledge, New York-London 2010, s. 17-42.

Reese S.D., Prologue - Framing Public Life: A Bridging Model for Media Research [w:] Framing Public Life: Perspectives on Media and Our Understanding of the Social World, red. S.D. Reese, O.H. Gandy, A.E. Grant, Routledge, London 2001, s. 7-31.

Schwalbe C.B., Remembering our Shared Past: Visually Framing the Iraq War on U.S. News Websites, „Journal of Computer-Mediated Communication” 2006, nr 12, s. 264-289.

Stöckl H., Lingwistyka mediów. O statusie i metodach (wciąz) konstytuującej się dyscypliny badawczej [w:] Lingwistyka mediów. Antologia tłumaczeń, red. R. Opiłouski, J. Jarosz, P. Stanieuski, Oficyna Wydawnicza Atut - Wrocłauskie Wydawnictwo Oświatowe-Neisse Verlag, Wrocław-Dresden 2015, s. 23-44.

Szylko-Kuas J., Wizerunki Prezydentów Rzeczpospolitej Polskiej: Bronisława Komorowskiego oraz Andrzeja Dudy - analiza porównawcza $w$ świetle teorii visual framing, „Res Rhetorica" 2019, nr 6(1), s. 30-50.

Van Gorp B., Strategies to Take Subjectivity Out of Framing Analysis [w:] Doing News Framing Analysis. Empirical and Theoretical Perspectives, red. P. D'Angelo, J.A. Kuypers, Routledge, New York-London 2010, s. 84-109. 